\title{
Can we improve parents' management of their children's postoperative pain at home?
}

\author{
Jill MacLaren Chorney PhD RPsych ${ }^{1,2}$, Alison Twycross PhD RN ${ }^{3}$, \\ Katherine Mifflin BSc(Hons) ${ }^{2}$, Karen Archibald LPN BA ${ }^{2}$
}

\begin{abstract}
J MacLaren Chorney, A Twycross, K Mifflin, K Archibald. Can we improve parents' management of their children's postoperative pain at home? Pain Res Manag 2014;19(4):e115-e123.
\end{abstract}

BACKGROUND: Thousands of children undergo surgery each year, and a shift toward same-day surgeries and decreased lengths of hospital stay results in parents being increasingly responsible for their child's postoperative care. Recent studies have tested interventions designed to improve parent management of their children's postoperative pain at home, but progress in this area has been limited by a lack of synthesis of these findings.

OBJECTIVE: To conduct a systematic review of interventions aimed at improving parent management of children's postoperative pain at home. METHODS: Articles evaluating interventions to improve management of their children's postoperative pain were identified using a library scientistdesigned search strategy applied in EMBASE, PubMed, CINAHL and PsycINFO. Two independent raters assessed each study for eligibility and extracted data.

RESULTS: Of the 147 articles identified for the review, eight met the inclusion criteria. Interventions included pain education, training in pain assessment, education on distraction, instruction in around-the-clock dosing and nurse coaching. Overall, results of comparisons of pain intensity and analgesic administration were modest. The intervention with the largest effect size was instruction in around-the-clock dosing, either alone or in combination with nurse coaching. Results of studies investigating pain assessment, pain education and distraction trials revealed small to medium effect sizes.

CONCLUSIONS: Results of trials investigating interventions to improve parent management of their children's postoperative pain at home were modest. Future studies should further examine barriers and facilitators to pain management to design more effective interventions.

Key Words: Acute pain; Children; Parent; Postoperative pain management; Systematic review

\section{Peut-on améliorer la prise en charge de la douleur postopératoire des enfants à la maison par leurs parents?}

HISTORIQUE : Des milliers d'enfants se font opérer chaque année. En raison de l'adoption des chirurgies d'un jour et du raccourcissement des séjours hospitaliers, les parents sont de plus en plus responsables des soins postopératoires de leur enfant. Des études récentes ont permis d'évaluer les interventions conçues pour améliorer la prise en charge de la douleur postopératoire des enfants à la maison par leurs parents, mais les progrès sont limités dans ce domaine, car ces observations n'ont pas été synthétisées.

OBJECTIF : Effectuer une analyse systématique des interventions pour améliorer la prise en charge de la douleur postopératoire des enfants à la maison par leurs parents.

MÉTHODOLOGIE : Les chercheurs ont repéré les articles évaluant les interventions visant à améliorer la prise en charge de la douleur postopératoire des enfants par leurs parents au moyen d'une stratégie de recherche conçue par un chercheur bibliothécaire, utilisé dans EMBASE, PubMed, CINAHL et PsycINFO. Deux évaluateurs indépendants ont examiné chaque étude pour en déterminer l'admissibilité et en extraire les données. RÉSULTATS : Des 147 articles extraits en vue d'analyse, huit respectaient les critères d'inclusion. Les interventions incluaient l'éducation sur la douleur, la formation sur l'évaluation de la douleur, l'éducation sur la distraction, les directives sur les doses à toute heure du jour et de la nuit et l'encadrement par une infirmière. Dans l'ensemble, les résultats des comparaisons sur l'intensité de la douleur et sur l'administration des analgésiques étaient modestes. Les directives sur les doses à toute heure du jour et de la nuit étaient l'intervention dont l'effet avait le plus d'ampleur, seule ou en association avec l'encadrement par une infirmière. Les résultats des études sur l'évaluation de la douleur, l'éducation sur la douleur et la distraction avaient une ampleur d'effet moyenne à modérée.

CONCLUSIONS : Les résultats des essais portant sur les interventions visant à améliorer la prise en charge de la douleur postopératoire des enfants à la maison par leur parent étaient modestes. D'autres études devraient s'attarder davantage sur les obstacles et les facilitateurs de prise en charge de la douleur afin de concevoir des interventions plus efficaces.

potent analgesics than recommended (9-11). Parents also may underuse nonpharmacological strategies, particularly deep breathing $(12,13)$.

There are numerous barriers to effective parent management of their children's pain at home. Parents often report misconceptions about adverse side effects of analgesics, fears of addiction and tolerance $(10,14,15)$, and they may doubt postoperative dosing instructions $(16,17)$. Children's response to pain is variable, as is their perceived need for treatment (ie, pain treatment thresholds); therefore, it is important that parents can recognize these thresholds and modify treatment accordingly $(18,19)$. Parents may also have limited knowledge of the impacts of postoperative pain or may believe that pain is an inevitable result of surgery (15). Parent familiarity with nonpharmacologial strategies may also be limited, particularly with regard to more advanced strategies such as relaxation, and parents may be unprepared to behaviourally manage children's refusal to take medications (20).

In an attempt to improve pain management, there have been studies investigating interventions that are directed toward parents. These interventions have often been designed to increase parental parents may provide too much analgesia $(7,8)$, most studies show that parents often give less than the prescribed doses of analgesics or use less

${ }^{1}$ Departments of Anesthesia, Pain Management and Perioperative Medicine, and Psychology, Dalhousie University; ${ }^{2}$ Centre for Pediatric Pain Research, IWK Health Centre, Halifax, Nova Scotia; ${ }^{3}$ Department of Children's Nursing, London South Bank University, London, United Kingdom

Correspondence: Dr Jill Chorney, Centre for Pediatric Pain Research, Eighth Floor (South), PO Box 9700, 5850 University Avenue, Halifax,

Nova Scotia B3K 6R8. Telephone 902-470-7707, fax 902-470-7709, e-mail jill.chorney@iwk.nshealth.ca 


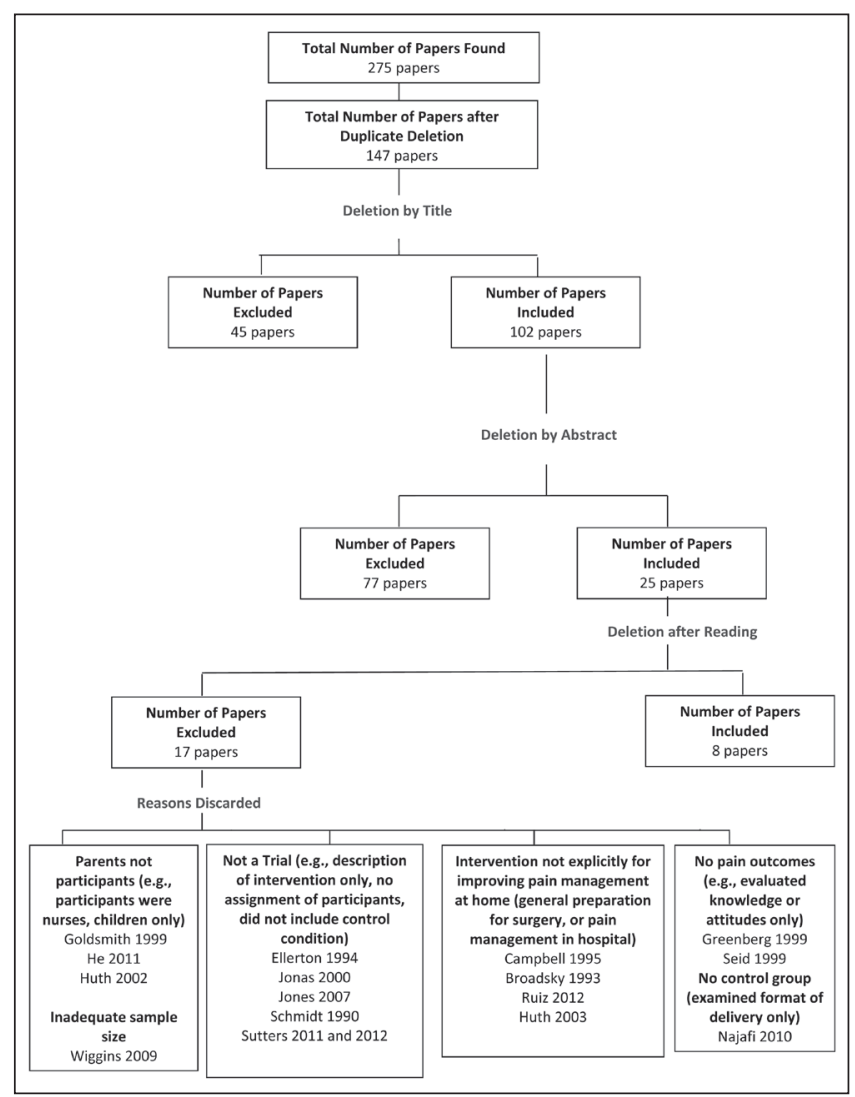

Figure 1) Details of search results and excluded articles

knowledge about analgesics, educate parents on the importance of managing pain, or to remind parents of adequate analgesic dosing. The lack of synthesis of these studies limits our ability to draw conclusions about potentially effective components of interventions or to guide clinical practice in this area. The current review systematically synthesizes studies examining interventions to improve parent management of their children's pain at home following surgery.

\section{METHODS}

\section{Search strategy}

The third author (KM) and a health sciences research librarian developed a search strategy to identify studies examining interventions to help improve parental pain management after day surgery. The search was based on key search terms/words (postoperative pain, postoperative, postsurgical, education, teach, train, home, parent, caregiver, mother, father, child) and included both subject headings (parent-child relations, professional-family relations) and thesaurus terms (MeSH, CINAHL, etc). Trucation/wild cards (eg, educat*, teach*) with Boolean operators (or/and) relevant to the search terms were also used to expand the search. The following databases were searched using this strategy: PubMed, CINAHL/Ebsco, PsycInfo, Web of Science, Cochrane Database and EMBASE. Reference lists from included articles were also examined for other relevant studies. The search included articles published from 1965 to May 2012.

\section{Selection of studies}

Inclusion criteria were: the study population included parents of infants, children or adolescents (zero to 18 years of age) who had undergone (or were about to undergo) surgery with general anesthetic; the study must have been an experimental or quasiexperimental trial including assignment of participants to conditions and at least 10 participants per group (with comparison groups including attention control or standard care); the study examined an intervention delivered to parents with the explicit aim to improve postoperative pain management provided by parents at home; the study must have included an outcome examining postoperative pain management (eg, pain intensity) or an analgesic administration measure (eg, number of doses administered).

Exclusion criteria were: lack of assignment of patients to groups; lack of inclusion of pain or analgesic outcome variables; and the intervention targeted only the child and had no parent component. Studies that examined preoperative preparation in general (eg, play therapy for children) were excluded unless they reported information that explicitly targeted parent management of pain at home. Studies that examined only the format of information (eg, written versus verbal) with no control condition were also excluded.

Two reviewers (KM and KA) screened search results by title and abstract for eligible studies. Articles that appeared to meet criteria at the title/abstract level were gathered for full review. The two reviewers examined these articles and independently assessed the articles for inclusion in the review. Disagreements were resolved through discussions with a third reviewer (JC).

\section{Data extraction and analyses}

One reviewer (KM) extracted all data, which was verified by a second reviewer to ensure all relevant data were included and accurate. Data on the following topics were extracted: sample characteristics, study design (randomized controlled trial, pretest-post-test, quasiexperimental, etc), method of treatment allocation, type of intervention and description of the intervention, major and minor outcomes with corresponding statistics.

To facilitate comparisons across studies, effect sizes (Cohen's d, ORs) were calculated. Cohen's d effect sizes are described in the text according to Cohen's conventions of 0.2 being considered 'small', approximately 0.5 being considered 'medium' and $>0.8$ being considered 'large' (21). Results are reported separately for each postoperative day. In the cases in which more than one assessment was administered on a postoperative day, the highest rating was used in the analysis. In the cases in which exact data (eg, means and SDs) for relevant analyses were not reported or reported only graphically, attempts were made to contact authors for this information. If these data were still not available, results of analyses reported in the original article were described. Risk of bias was assessed by the first author (JC) using the Cochrane Collaboration Risk of Bias Assessment tool. Risk was rated as low, high or unclear within each category.

\section{Included study characteristics}

\section{RESULTS}

Figure 1 presents the articles generated through the literature search and those meeting inclusion criteria. A total of 275 articles were found in all databases; 128 of these were duplicates included in more than one database, leaving 147 titles for review. Forty-five articles were discarded after title review and an additional 77 were discarded on abstract review, leaving 25 articles for full manuscript review. Of these 25 articles, 17 did not meet inclusion criteria. Reasons for exclusion are presented in Figure 1. Of note, two excluded studies were trials of interventions that would otherwise have met criteria for the present review, but did not include pain outcomes. Greenberg et al (22) evaluated pain and pain management information delivered by video, but included measures of knowledge and attitudes only, not pain management practices or children's pain. Seid and Varni (23) evaluated an intervention to teach parents to assess pain and provide analgesics based on assessment, but only included outcomes of length of hospital stay, days of school missed and parent satisfaction with pain management.

Characteristics of included studies are shown in Table 1. Eight articles met inclusion criteria for the present review (24-31). The majority of studies were published manuscripts; one was a dissertation (26).

Patient populations: The final articles included children ranging in age from one to 18 years, with the majority of studies including children from three to 12 years of age. Most of the studies included children undergoing planned day surgery. Three studies included 
TABLE 1

Characteristics of included studies

\begin{tabular}{|c|c|c|c|c|}
\hline $\begin{array}{l}\text { First author } \\
\text { (reference), year }\end{array}$ & Age & Surgery & Sample size & Control \\
\hline $\begin{array}{l}\text { Chambers et al } \\
(24), 1997\end{array}$ & $\begin{array}{l}\text { 2-12 years; } \\
\text { mean } \pm \\
\text { SD } \\
4.3 \pm 2.4 \\
\text { years }\end{array}$ & $\begin{array}{l}\text { Tonsillectomy and } \\
\text { adenoidectomy, } \\
\text { circumcision, } \\
\text { hernia repair, } \\
\text { strabismus } \pm \\
\text { repair, orchidopexy, } \\
\text { dental extraction } \\
\text { and restorations }\end{array}$ & $\begin{array}{l}\text { n=82; control, } \\
\text { n=27; pain } \\
\text { education, } n=27 ; \\
\text { pain assessment, } \\
n=28\end{array}$ & $\begin{array}{l}\text { Written information: General surgery } \\
\text { preparation pamphlet in addition to } \\
\text { 'standard care' } \\
\text { Administered preoperatively by mail }\end{array}$ \\
\hline $\begin{array}{l}\text { Sutters et al } \\
(28), 2004\end{array}$ & $6-15$ years & $\begin{array}{l}\text { Tonsillectomy } \pm \\
\text { adenoidectomy } \pm \\
\text { myringotomy }\end{array}$ & $\begin{array}{l}n=80 ; \text { control/PRN, } \\
n=28 ; \text { ATC } n=26 ; \\
\text { ATC + nurse } \\
\text { coaching, } n=26\end{array}$ & $\begin{array}{l}\text { Written information: Dose } \\
\text { administration, instructions on activity } \\
\text { restrictions, school attendance, } \\
\text { postoperative bleeding, diet, ear and } \\
\text { throat pain, analgesic administration, } \\
\text { possible changes in sleep patterns, } \\
\text { expected appearance of the back of } \\
\text { the throat, fever and the follow-up } \\
\text { appointment with the surgeon. Timing } \\
\text { of provision unclear }\end{array}$ \\
\hline
\end{tabular}

\begin{tabular}{|c|c|c|c|}
\hline $\begin{array}{l}\text { Franck et al } \\
(25), 2007\end{array}$ & $6-12$ years & $\begin{array}{l}\text { Planned day } \\
\text { surgery }\end{array}$ & $\begin{array}{l}\text { n=25: control, } \\
n=10 ; \\
\text { intervention, } \\
n=15\end{array}$ \\
\hline $\begin{array}{l}\text { Helgadottir (26), } \\
2007\end{array}$ & $\begin{array}{l}\text { 3-7 years; } \\
\text { mean } \pm S D \\
5.27 \pm 1.12 \\
\text { years }\end{array}$ & $\begin{array}{l}\text { Tonsillectomy with/ } \\
\text { without minor } \\
\text { procedures }\end{array}$ & $\begin{array}{l}n=27 \text { : control } \\
n=13 ; \\
\text { intervention, } \\
n=14\end{array}$ \\
\hline
\end{tabular}
Verbal information: Pain assessment and use of paper pain scale. Provided preoperatively

Verbal and written information: ATC medication dosing instructions (including waking at night for dose), education about types of acetaminophen, pain assessment, consequences of inadequate pain management, education about addiction. Timing unclear

\begin{tabular}{|c|c|c|c|}
\hline $\begin{array}{l}\text { Unsworth et al } \\
\text { (30), } 2007\end{array}$ & $4-12$ years & $\begin{array}{l}\text { Tonsillectomy } \pm \\
\text { adenoidectomy } \pm \\
\text { grommet insertion }\end{array}$ & $\begin{array}{l}n=72 \text { : control, } \\
n=39 ; \\
\text { intervention, } \\
n=33\end{array}$ \\
\hline
\end{tabular}

Verbal information: Analgesic administration instructions: administer paracetamol for mild pain, or ibuprofen for moderate to severe pain. Administer codeine if pain not improved within $1 \mathrm{~h}$. No instructions on how to determine mild, moderate or severe pain. Provided postoperatively

ATC: Additional written information: Instructions in use of digital timer to remind of dose. Timing of provision unclear. ATC + coaching: Written information from ATC group. Additional verbal information and coaching: evaluation of the child's current condition, review of the pain intensity scores, verification that the child was taking the pain medication, re-education regarding the rationale for ATC dosing, review of strategies to facilitate medication administration, and re-education about potential side effects associated with analgesic administration. Provided during follow-up telephone calls

Pain assessment only: Additional verbal information on use of temporary tattoo of Wong-Baker Faces Pain Scale. Tattoo placed postoperatively

Nonpharmacological strategies: Additional verbal and written information: use of distraction. Timing unclear

Pain assessment only: Modified verbal information: instructions in use of Wong-Baker Faces Pain Scale. Analgesic administration instructions based on Wong-Baker score (paracetamol for scores 1, 2 and 3, ibuprofen for scores 4 and 5 . If child reported a score of $51 \mathrm{~h}$ after ibuprofen, administer codeine). Provided postoperatively

\begin{tabular}{|c|c|c|c|c|c|}
\hline $\begin{array}{l}\text { Kankkunen et al } \\
(27), 2009\end{array}$ & $\begin{array}{l}\text { 1-2 years; } \\
\text { mean } 22 \\
\text { months }\end{array}$ & Day surgery & $\begin{array}{l}\mathrm{n}=50 \text { : control, } \\
\mathrm{n}=19 ; \\
\text { intervention, } \mathrm{n}=29\end{array}$ & $\begin{array}{l}\text { Verbal information: Timing and dosing } \\
\text { the analgesics, contact information for } \\
\text { the surgical ward. Timing unclear }\end{array}$ & $\begin{array}{l}\text { Pain assessment only: Instructions on use of } \\
\text { Parent's Post-Operative Pain Measure. Timing } \\
\text { unclear }\end{array}$ \\
\hline $\begin{array}{l}\text { Sutters et al } \\
\text { (29), } 2010\end{array}$ & $6-15$ years & $\begin{array}{l}\text { Tonsillectomy } \pm \\
\text { concurrent minor } \\
\text { procedures }\end{array}$ & $\begin{array}{l}\mathrm{n}=113: \text { PRN, } \\
\text { n=39; ATC, } n=34 ; \\
\text { ATC + nurse } \\
\text { coaching, } n=40\end{array}$ & Same as Sutters et al (28), 2004 & $\begin{array}{l}\text { ATC, ATC + coaching: Same as Sutters et al } \\
(28), 2004\end{array}$ \\
\hline $\begin{array}{l}\text { Vincent et al } \\
\text { (31), } 2012\end{array}$ & $\begin{array}{l}\text { 7-17 years; } \\
\text { mean } \pm \\
\text { SD } \\
13.7 \pm 2.5 \\
\text { years }\end{array}$ & $\begin{array}{l}\text { Any child } \\
\text { hospitalized for at } \\
\text { least } 23 \mathrm{~h} \text { and } \\
\text { sent home with an } \\
\text { analgesic } \\
\text { prescription }\end{array}$ & $\begin{array}{l}n=108 \text { : control, } \\
n=55 ; \\
\text { intervention, } \\
n=53\end{array}$ & $\begin{array}{l}\text { Standard care: No protocol, health care } \\
\text { provider-dependent }\end{array}$ & $\begin{array}{l}\text { Pain education and assessment: Verbal and } \\
\text { written information: consequences of unrelieved } \\
\text { pain, pain assessments, pharmacological and } \\
\text { nonpharmacological treatment and concerns } \\
\text { about analgesics. Assess parent understanding } \\
\text { of analgesics' adverse effects and of addiction. } \\
\text { Timing unclear }\end{array}$ \\
\hline
\end{tabular}

ATC Around the Clock; PRN Pro re nata, as needed

exclusively tonsillectomy with/without associated procedures (28-30) and four studies used mixed day surgery procedures (24-27). One study included children undergoing surgeries requiring hospitalization (31). Control groups: Most studies used control conditions that included some form of pain-related information. These conditions often included information on pain assessment, timing and dosing of analgesics, and postoperative recovery expectations (25-30). Two studies used standard care as their control condition $(24,31)$, but did not provide information on clinical practice in postoperative pain education. Although one of these studies used a control condition involving 
a general surgery preparation booklet, there was no information regarding what information was typically offered by clinical staff (24). Types of interventions: Most studies examined some form of educational intervention, usually including information about pain sources, pain assessment, and pharmacological and nonpharmacological pain treatment options. Chambers et al (24) provided this information in a written pamphlet mailed to families before surgery. Vincent et al (31) provided this information in verbal and written form. Of note, these studies both compared their interventions with standard care (or standard care plus a general surgery pamphlet). In addition to their 'pain education' condition, Chambers et al (24) included a 'pain assessment control' condition in their study. This condition included information about a general hospital visit (from the 'standard care' control condition) in addition to specific information about pain assessment (a section from the 'pain education' condition). Because this condition examined the addition of information about pain assessment to more general information about the hospital, it is treated as an intervention condition for the purpose of the present review (24).

Three studies aimed to teach parents to use a specific pain assessment tool via written and verbal instructions (in addition to pain education included in both the control and intervention groups). Franck et al (25) provided children with a temporary tattoo of the Wong-Baker Faces Pain Scale with the goal of promoting pain assessment; Unsworth et al (30) provided specific training in analgesic administration based on Wong-Baker Faces Pain Scale scores; and Kankkunen et al (27) taught parents to use the Parents' Postoperative Pain Measure (11).

One study (26) included specific verbal and written information about the use of nonpharmacological strategies (distraction). As with other studies, Helgadottir (26) provided standard written and verbal information about pain assessment, consequences of undermanaged pain and pharmacological pain management in both their control and intervention groups.

The most intensive interventions were offered in the studies by Sutters et al $(28,29)$. These studies included standard written information regarding pain and pain management for all groups. The aroundthe-clock (ATC) intervention group had an additional instruction to use a timer to remember to provide analgesic doses. The ATC plus nurse coaching group received the timer reminder as well as additional verbal coaching on strategies to improve adherence, rationale for use of combined opioid and nonopioid treatments and myths about psychological addiction. Nurse coaching was provided around the time of surgery and by telephone when parents had returned home. Of note, Sutters et al (29) reported no difference between their ATC and ATC plus coaching groups; thus, these groups were treated as one for analyses.

\section{Study outcomes}

Pain outcomes: Results of pain outcome measures are shown in Table 2. Although one study used a pain intensity assessment tool in their intervention (Wong-Baker Faces Pain Scale), the authors did not report on the results on pain intensity between groups (30). The remaining studies included parent report $(24,26,27)$ or child selfreport $(25,26,28,29,31)$. Parent report was provided using the Parents' Postoperative Pain Measure in one study (26), a visual analogue scale in another (24) and a five-point Likert scale in an additional study (27). Of note, although Kankkunen et al (27) used the Parents' Postoperative Pain Measure as an intervention, they did not administer this tool to both groups and, thus, do not report their betweengroups comparison using this measure. Children's self-report of pain was collected using the Wong-Baker Faces Pain Scale in two studies $(25,26)$, an 11-point numerical rating scale in three studies $(28,29,31)$ and the Faces Pain Scale - Revised in one study (31). Most studies administered pain measures more than once per day. Three studies assessed pain with and without pain provocation $(26,28,29)$.

Three studies demonstrated at least medium effect sizes favouring the intervention $(24,26,29)$. Chambers et al $(24)$ found a medium effect size favouring their assessment condition on postoperative day 3 , but not postoperative days 1 or 2 . One of the studies by Sutters et al (29) found a medium effect size favouring their ATC condition on pain with provocation on all postoperative days, and without provocation on postoperative days 2 and 3 (effect size without provocation on postoperative day 1 was small). Helgadottir (26) found a medium and large effect size favouring their nonpharmacological strategies group on pain with and without provocation, respectively, on postoperative day 2. Most other effect sizes favouring the intervention conditions were $<0.2$. Two studies found small effect sizes favouring the control condition. Sutters (28) found a small effect size favouring the control condition, but only with pain provocation and only on postoperative day 2. Vincent (31) found small effect sizes favouring the control condition on postoperative days 1 and 3. Results of one study were mixed, with an OR favouring the intervention on postoperative day one and favouring the control group on postoperative day 2 (27). One study did not provide pain scores, but noted in their article that there was no difference between control and intervention conditions (25).

Of note, there was relative consistency in pain scores across studies. Scores on the first postoperative day typically fell in the range of $30 \%$ to $50 \%$ of the maximum score on a scale (eg, between 3 and 5 on a 0 to 10 scale), indicating moderate pain. Most studies report that pain scores decrease over time, but are in the mild to moderate range up to postoperative day three. No studies examined pain at time points after three days postoperatively.

Analgesic outcomes: Results of analgesic outcomes are shown in Table 3. The majority of studies assessed the number of doses of analgesic medications per day with the most common analgesic being acetaminophen. One study reported on the number of doses that were provided in the 'expected optimal range', but it is difficult to ascertain from these results whether these data represent all administrations of analgesics or just those that were at the prescribed or recommended dose (27). Four studies reported amount of analgesic administered (generally $\mathrm{mg} / \mathrm{kg}$ ) instead of or in addition to number of doses (26,28-30).

Overall, effect sizes were small to medium. The two studies evaluating ATC dosing interventions showed large effects sizes ranging from 1.14 to 1.72 across postoperative days $(28,29)$. Chambers et al $(24)$ found a medium effect size favouring their pain education condition on postoperative day three and small effect sizes favouring this condition on postoperative days 1 and 2. Chambers et al (24) found a small effect size favouring their pain assessment condition, and Vincent et al (31) found a small effect size favouring their pain education and assessment condition, both on postoperative day 2 only. Helgadottir (26) found a small effect size favouring the control condition on postoperative day 1 . Of note, this study examined education in the use of nonpharmacological strategies; thus, this finding may be in line with the intervention training.

Other outcomes: Chambers et al (24) examined parent attitudes about pain medication using the Medication Attitudes Questionnaire (14) and found a large effect size $(\mathrm{d}=0.71)$ favouring the pain assessment and education intervention over the control condition. The effect size comparing the pain assessment and control conditions in this study was minimal $(\mathrm{d}=0.05)$. Several studies reported on parent general impressions of pain management or satisfaction with pain management. No studies found statistically significant differences between intervention or control groups, but parents generally reported high satisfaction with pain management across groups. The two studies by Sutters et al $(28,29)$ reported on potential side effects (eg, sedation, nausea) and found no difference between groups (ATC and standard care). There was also no difference between groups for unplanned health care use (31). Of note, with the exception of the Medication Attitudes Questionnaire, most of the methods of assessment of these other outcomes were nonvalidated scales, single items or responses to open-ended questions.

\section{Risk of bias assessment}

Results of the risk of bias assessment are presented in Table 4. Most studies were described as randomized trials, but the generation of allocation sequence was either unclear or not truly random in several cases. For 
TABLE 2

Results of pain outcome measurements

\begin{tabular}{ll}
\hline Author (reference), year & \multicolumn{1}{c}{ Measure used } \\
\hline $\begin{array}{ll}\text { Chambers et al (24), } & \text { Parent report } 100 \mathrm{~mm} \text { visual analogue scale. } \\
1997 & \text { Administered } 5 \text { times per day on each of the first } \\
& \text { 3 PODs. Highest pain score each day used as } \\
& \text { outcome }\end{array}$
\end{tabular}
outcome
Sutters et al (28), 2004 Child report on numerical rating scale from 0 (no pain) to 10 (worst pain imaginable). Administered with and without swallowing before bedtime and on awakening over first 3 PODs. Highest pain score each day used as outcome
Franck et al (25), 2007 Child report on Wong-Baker Faces Pain Scale. Used whenever child reported pain or parent asked about pain over the first 3 PODs

Helgadottir (26), 2007 Child report on Wong-Baker Faces Pain Scale. Administered on each of POD 1 and 2 when swallowing and not swallowing at 5 timepoints each day. Highest pain score each day used as outcome Parent report on Parent's Postoperative Pain Measure. Administered twice each day on PODs 1 and 2

Control group $\quad$ Outcome

POD 1=32.0 \pm 34.8

POD $2=20.9 \pm 26.0$

POD $3=11.9 \pm 19.0$

Experimental group

Education booklet

POD $1=31.5 \pm 26.0$

POD $2=19.7 \pm 25.20$

POD $3=14.3 \pm 20.5$

Assessment booklet

POD $1=29.0 \pm 26.0$

POD $2=17.3 \pm 17.8$

POD $3=6.1 \pm 10.1$

(Assessed without swallowing) ATC

POD 1=5.1 \pm 3.1

POD $2=4.5 \pm 3.0$

POD $3=3.2 \pm 3.0$

(Assessed with swallowing)

POD $1=4.9 \pm 3.2$

POD $2=3.9 \pm 2.6$

POD $3=3.1 \pm 2.8$

POD 1=5.2 \pm 2.4

POD $2=4.3 \pm 3.3$

POD $3=3.5 \pm 2.4$

POD $1=5.2 \pm 2.6$

POD $2=4.7 \pm 2.8$

(Assessed without swallowing)

(Assessed with swallowing)

POD $3=3.1 \pm 2.7$

ATC plus coaching

(Assessed without swallowing)

POD $1=5.5+2.3$

POD $2=4.1 \pm 2.5$

POD $3=2.9 \pm 2.3$

(Assessed with swallowing)

POD 1 $=5.4 \pm 2.5$

POD $2=4.0 \pm 2.3$

POD $3=2.9 \pm 2.4$

Not reported. From text: "Parents and children generally reported only mild pain intensity for children at rest or with movement." (p. 336)

Child report

(Assessed with swallowing)

POD $1=3.2 \pm 1.2$

POD $2=3.3 \pm 1.6$

(Assessed without swallowing)

POD $1=3.8 \pm 1.2$

POD 2=4.3 \pm 1.1

Parent report

POD $1=7.9 \pm 3.8$

POD $2=6.2 \pm 4.2$
Child report

(Assessed with swallowing)

POD $1=3.3 \pm 1.5$

POD $2=2.4 \pm 1.4$

(Assessed without swallowing)

POD $1=3.7 \pm 1.5$

POD $2=3.3 \pm 1.1$

Parent report

POD $1=8.3 \pm 4.8$

POD $2=6.7 \pm 4.9$

POD 1: $41 \%$ mild/moderate pain

POD 2: $36 \%$ mild/moderate

pain

POD 2: $21 \%$ mild pain or greater

(Assessed without swallowing)

POD $1=4.3 \pm 2.8$

POD $2=5.0 \pm 2.9$

POD $3=4.1 \pm 2.7$

(Assessed with swallowing)

POD 1 $=4.9 \pm 2.8$

POD $2=5.0 \pm 2.9$

POD $3=4.2 \pm 3.0$

POD $1=4.4 \pm 1.8$

POD $2=4.3 \pm 1.8$

POD $3=3.8 \pm 2.5$

(Assessed without swallowing)
POD $1=3.7 \pm 2.4 \quad d=-0.24$

POD $2=3.2 \pm 2.9 \quad d=-0.62$

POD $3=3.1 \pm 2.3$

$\mathrm{d}=-0.41$

(Assessed with swallowing)

POD $1=3.8 \pm 2.5$

POD $2=3.3 \pm 2.8$

POD $3=3.3 \pm 2.5$

POD 1=4.8 \pm 2.1

POD 2=4.4 \pm 2.1

POD $3=4.3 \pm 2.0$

$\mathrm{d}=-0.42$

$\mathrm{d}=-0.60$

$d=-0.34$

$d=0.21$

$d=0.05$

$d=0.22$
Effect size

$d=-0.02$

$d=-0.05$

$d=0.12$

$d=-0.09$

$d=-0.16$

$d=-0.38$

$d=0.04$

$d=-0.06$

$d=0.11$

$d=0.01$

$d=0.29$

$d=0$

$\mathrm{d}=0.15$

$d=-0.15$

$d=-0.12$

$d=0.18$

$d=0.04$

$d=-0.08$

$d=0.07$

$d=-0.60$

$d=-0.07$

$d=-0.91$

$d=0.09$

$d=0.10$

$\mathrm{OR}=0.63$

$\mathrm{OR}=1.99$

Administered once daily for three days postoperatively

Data presented as mean \pm SD unless otherwise indicated. Negative effect sizes favour intervention. ATC Around the clock; POD Postoperative day 
TABLE 3

Results of analgesic use outcome measures

\begin{tabular}{l}
\hline Author (reference), year \\
\hline Chambers et al (24), $1997 \begin{array}{r}\text { Mean number of doses per day (acetaminophen, amount } \\
\text { per dose not reported) }\end{array}$ \\
Sutters et al (28), 2004 $\quad \begin{array}{l}\text { Mean amount (in millilitres) per day (acetaminophen } 120 \mathrm{mg} / 5 \mathrm{~mL} \\
\text { with codeine } 12 \mathrm{mg} / 5 \mathrm{~mL} \text { ) }\end{array}$
\end{tabular}

POD $1=54.6 \pm 26.5$

POD $2=43.8 \pm 28.2$

POD $3=31.2 \pm 30.2$

\begin{tabular}{ll}
\multicolumn{1}{c}{ Intervention } & Effect size \\
Education booklet & \\
POD 1 $=2.2 \pm 1.8$ & $\mathrm{~d}=0.35$ \\
POD $2=1.4 \pm 1.7$ & $\mathrm{~d}=0.43$ \\
POD $3=0.8 \pm 1.2$ & $\mathrm{~d}=0.50$ \\
Assessment booklet & \\
POD 1=1.7 \pm 1.4 & $\mathrm{~d}=0.07$ \\
POD 2 $=1.2 \pm 1.1$ & $\mathrm{~d}=0.38$ \\
POD 3 $=0.2 \pm 0.5$ & $\mathrm{~d}=0$
\end{tabular}

\section{ATC}

POD $2=76.0 \pm 17.7 \quad d=1.47$

POD $3=71.7 \pm 18.2 \quad d=1.76$

ATC plus coaching

POD $1=75.0 \pm 14.5 \quad \mathrm{~d}=1.05$

POD $2=76.2 \pm 17.3 \quad d=1.49$

POD $3=73.2 \pm 21.6 \quad d=1.69$

Franck et al (25), $2007 \quad$ Number of doses

Helgadottir (26), $2007 \quad$ Mean number of doses and total amount (mg/kg) per day (acetaminophen)

Not reported

Number of doses

POD $1=4.2 \pm 0.42$

POD 2=3.8 \pm 0.63

Amount $(\mathrm{mg} / \mathrm{kg})$

POD $1=59.3 \pm 6.8$

POD $2=50.7 \pm 10.4$

Unsworth et al (30), 2007 Median number of doses per day (acetaminophen $20 \mathrm{mg} / \mathrm{kg} / \mathrm{dose}$ ) or ibuprofen $6 \mathrm{mg} / \mathrm{kg} /$ dose or codeine $(\mathrm{mg} / \mathrm{kg})$

$\operatorname{POD} 1=4$

POD 2 $=5$

POD $3=5$

POD $1=3.86 \pm 1.62$
Number of doses

POD 1=4.1 \pm 0.54

POD 2=3.8 \pm 0.75

Amount (mg/kg)

POD 1 $=56.0 \pm 9.5$

POD $2=52.4 \pm 13.4$

POD $1=4$

POD 2=5

POD $3=5$

POD 2=3.86 \pm 1.62

POD $2=3.81 \pm 0.75$ $d=-0.21$

$d=0.00$

$d=-0.40$

$d=0.14$

N/A

$d=0.04$

$d=0.04$
POD $1=3.81 \pm 0.75$

2009

Sutters et al (29), 2010

$$
\text { Naproxen: } 10 \text { mg/kg, }
$$

Paracetamol: $60 \mathrm{mg} / \mathrm{kg}$

Ibuprofen: $20-40 \mathrm{mg} / \mathrm{kg}$

Ketoprofen: $3-5 \mathrm{mg} / \mathrm{kg}$

Mean amount (in millilitres) per day (acetaminophen $167 \mathrm{mg} / 5 \mathrm{~mL}$
with hydrocodone $2.5 \mathrm{mg} / 5 \mathrm{~mL}$ )

POD $1=42.3 \pm 18.4$

POD 2 $=36.2 \pm 14.7$

POD $3=34.2 \pm 17.0$

Vincent et al (31), 2012
Mean percentage of possible doses per day (type of analgesic not reported)
POD $1=66.7 \pm 27.1$

POD 2 $=57.6 \pm 29.8$

POD $3=43.3 \pm 35.6$
POD $1=58.0 \pm 10.2$

$d=1.16$

POD 2=57.3 \pm 12.2

POD $3=53.5 \pm 14.4$

POD $1=70.1 \pm 22.0$

POD 2 $=62.0 \pm 21.9$

POD $3=55.2 \pm 27.5$

\section{$d=1.61$}

$d=1.26$

$\mathrm{d}=0.14$

$\mathrm{d}=0.17$

$d=0.38$

ATC Around the clock; POD Postoperative day

example, Franck et al (25) randomly assigned time periods of one week to each condition, but all children recruited in that week were assigned to the same condition (25). It is possible that there was some systematic bias in when children were scheduled for surgery that may have influenced results (eg, staffing may have been different on different weeks). Kankkunen et al (27) alternated in assignment of participants to condition and informed potential participants of their condition before consent. This procedure was likely to influence results because more parents chose not to participate in the control condition. The nature of treatment conditions made it difficult to blind participants or assessors to condition, but two studies reported that the treatment providers were blinded to condition assignment $(24,26)$. Most studies had relatively complete outcome data, and relatively similar attrition rates and availability of outcome data across study groups. It is notable, however, that attrition was present in all studies - ranging from 6\% (27) to 28\% (31).

\section{DISCUSSION}

The purpose of the present study was to provide a systematic review of interventions to improve parent management of their children's postoperative pain at home. The content of interventions were mixed across studies and included written or verbal information (eg, consequences of undermanaged pain, pain treatment), training in pain assessment, instructions on ATC dosing or additional support through follow-up telephone calls.

Overall, the results of trials on children's pain intensity were variable and fell within effect size ranges that would generally be considered small to medium based on Cohen's definition. Results for administration of analgesics were somewhat larger than those for pain intensity, with studies using ATC dosing demonstrating large effect sizes, corresponding to approximately one to two more doses of analgesics per day. In contrast to studies showing increased analgesic dosing, the one study that trained parents to use distraction showed a medium effect size favouring the control condition; parents who were trained in using distraction administered fewer analgesics than those not trained in distraction on the first postoperative day. It is possible that parents who were trained to use distraction believed that this strategy had been effective in managing children's pain and, therefore, they administered fewer analgesics. There were few differences in 
TABLE 4

Risk of bias assessment

\begin{tabular}{|c|c|c|c|c|c|}
\hline $\begin{array}{l}\text { Author } \\
\text { (reference), } \\
\text { year }\end{array}$ & $\begin{array}{c}\text { Random sequence } \\
\text { generation }\end{array}$ & Allocation concealment & Blinding & $\begin{array}{l}\text { Incomplete } \\
\text { outcome } \\
\text { data }\end{array}$ & $\begin{array}{l}\text { Selective } \\
\text { reporting }\end{array}$ \\
\hline $\begin{array}{l}\text { Chambers et al } \\
(24), 1997\end{array}$ & $\begin{array}{l}\text { Unclear. Allocation } \\
\text { described as "random" but } \\
\text { no information provided on } \\
\text { how sequence was } \\
\text { generated }\end{array}$ & $\begin{array}{l}\text { Unclear. No information on } \\
\text { whether allocation sequence } \\
\text { was concealed }\end{array}$ & $\begin{array}{l}\text { Participants: Low risk. Providers: Low risk. Assessors: } \\
\text { Unclear. Telephone calls made by assessors and it is } \\
\text { not stated if they were blinded to condition }\end{array}$ & Low risk & Low risk \\
\hline $\begin{array}{l}\text { Sutters et al } \\
(28), 2004\end{array}$ & Low risk & $\begin{array}{l}\text { Unclear. Allocation by SPSS } \\
\text { (IBM Corporation, USA) } \\
\text { random number generator, } \\
\text { but unclear on whether this } \\
\text { sequence was generated at } \\
\text { the outset and concealed or } \\
\text { completed for each } \\
\text { participant }\end{array}$ & $\begin{array}{l}\text { Participants: High risk. Due to nature of condition, } \\
\text { parent was aware of assignment. Could have } \\
\text { influenced results. Providers: High risk. Same as for } \\
\text { participants. Assessors: not applicable; parent } \\
\text { completed assessments on own }\end{array}$ & Low risk & Low risk \\
\hline $\begin{array}{r}\text { Franck et al } \\
(25), 2007\end{array}$ & $\begin{array}{l}\text { High risk. Random } \\
\text { allocation sequence was } \\
\text { randomly generated for } \\
\text { one week time blocks, not } \\
\text { per participant. Therefore, } \\
\text { participants recruited }\end{array}$ & $\begin{array}{l}\text { High risk. Allocation of } \\
\text { sequence was revealed after } \\
\text { first child in one week block } \\
\text { was assigned }\end{array}$ & $\begin{array}{l}\text { Participants: High risk. Due to nature of condition } \\
\text { (visible tattoo), parent was aware of assignment. } \\
\text { Providers: High risk. Same as above. Assessors: } \\
\text { High risk. Same as above }\end{array}$ & Low risk & $\begin{array}{l}\text { High risk: Pain } \\
\text { outcomes } \\
\text { reported } \\
\text { incompletely } \\
\text { (no values } \\
\text { reported) }\end{array}$ \\
\hline
\end{tabular}
randomly assigned to condition

\begin{tabular}{|c|c|c|}
\hline $\begin{array}{l}\text { Helgadottir } \\
\text { (26), } 2007\end{array}$ & Low risk & $\begin{array}{l}\text { Unclear. No information on } \\
\text { whether allocation sequence } \\
\text { was concealed }\end{array}$ \\
\hline Unsworth et al & Low risk & Low risk \\
\hline
\end{tabular}

(30), 2007

$\begin{aligned} \text { Kankkunen et } & \text { High risk. Alternating } \\ \text { al (27), 2009 } & \text { sampling and more } \\ & \text { potential participants } \\ & \text { chose not to participate in } \\ & \text { the control group }\end{aligned}$

Sutters et al Low risk

(29), 2010

Vincent et al

(31), 2012

\section{High risk. Allocation was alternating; thus, was not concealed}

\footnotetext{
Unclear. Allocation by SPSS random number generator, but unclear on whether this sequence was generated at the outset and concealed or completed for each participant
}

High risk. All control participants recruited first, followed by all intervention participants

\section{High risk. All control} participants recruited first, followed by all intervention participants
Participants: High risk. Providers: Low risk. Assessors: Low risk Low risk Unclear. Telephone calls made by assessors and it is not stated if they were blinded to condition

Participants: High risk. Due to nature of condition, parent was aware of assignment. Providers: Unclear. No information provided. Assessors: Not applicable; parent completed assessments on own

Participants: High risk. Allocation was informed before Low risk consent. Providers: Unclear. No information provided

Assessors: Not applicable; parent completed assessments on own

Participants: High risk. Due to nature of condition, Low risk Low risk parent was aware of assignment. Could have influenced results. Providers: High risk. Same as for participants. Assessors: Not applicable; parent completed assessments on own

Participants: High risk. Due to nature of condition, Low risk Low risk parent was aware of assignment. Could have influenced results. Providers: High risk. Aware of group assignment due to allocation sequence. Assessors: High risk. Aware of group assignment due to allocation sequence other outcomes that were assessed (eg, satisfaction), with the exception of one study finding more positive attitudes about pain medications for parents who received pain education compared with those who did not. Overall, instruction on ATC dosing appeared to be the most promising intervention, with pain education and training in pain assessment being less effective. Of note, adding a relatively resourceintensive intervention of nurse follow-up telephone calls did not appear to increase the efficacy of instruction in ATC dosing.

In the case of data reported here, a medium effect size on pain intensity corresponded to approximately $20 \%$ difference in pain scores between intervention and control conditions. The issue of magnitude of effect size versus clinically meaningful change in pain warrants further discussion. Benchmarks for clinically significant change in pain have been put forth, with recent Initiative on Methods, Measurement, and Pain Assessment in Clinical Trials definitions of minimally important decreases as between $10 \%$ and $20 \%$, moderately important decreases as $>30 \%$ and substantial decreases as $>50 \%$ (32). Although these benchmarks have been adopted in some cases, it is important to note that they were developed in the context of adult chronic pain data, and the validity of these cutoffs has not been established in children or in postoperative contexts. The nature of the rapid improvement in pain over time could also result in floor effects over later postoperative days, thereby potentially minimizing intervention effects. If this is the case, reporting categorical outcomes, such as the 
proportion of children who continue to experience moderate to severe pain on later postoperative days, may be more meaningful than group means. It is widely acknowledged that pain is a subjective phenomenon, and it is reasonable to assume that the need for pain treatment is similarly subjective. Indeed, several studies have found significant variability in the level of pain at which children report a perceived need for treatment (pain treatment thresholds) $(18,19)$. Examining group differences in single-item intensity scores ignores inter- and intraindividual variability in pain experiences and, thus, may not adequately describe the experiences of children in each intervention condition. Future studies should consider reporting on both absolute pain intensity and some relative pain measure (eg, pain exceeding an individually set treatment threshold) (33).

Methodological considerations of the included studies should be noted in the interpretation of these results. First, the lack of significant differences between intervention and control conditions is some studies may be due to the nature of the control groups. Most studies provided information about pain as part of their control conditions and, therefore, examined only the incremental improvement of adding information on pain assessment, distraction or ATC dosing with/ without nurse coaching. It is possible that pain education improved outcomes as much as could be expected with these types of interventions. The results of the two studies that attempted to examine the impact of pain education are also difficult to interpret because their control groups were standard care, and it is possible that control parents received the same information as the parents in the intervention. Measurement issues in some of these studies should also be noted. Two studies used the Wong-Baker Faces Pain Scale; although this tool has been validated in the context of postoperative pain, concerns have been raised about potential anchor effects (34). Timing of measurement is also a consideration in interpreting these studies. Many studies assessed pain at multiple time points during the day, and some chose only the most severe time point for analysis or collapsed across ratings. Finally, the lack of examination of age and sex effects are notable given the relatively wide age range in several of the studies (eg, two to 12 years of age) and the inclusion of both boys and girls in all samples. Given the developmental changes in children's ability to participate in their own care, parent roles in managing children's postoperative pain would likely be different in young children compared with older children (35). In this way, it is possible that differential effects of these interventions may be found across child age. Sex differences were also not examined in any of these studies, despite more recent evidence suggesting potential differences in pain and pain management between boys and girls, especially after puberty (36).

Despite these limitations, the clear pattern of modest results suggests that there is still room to improve children's pain management at home. To date, the development of interventions may have been limited by the lack of theory-driven conceptualization. Although some studies cite a theoretical framework, there is rarely a discussion of how the specific content of the intervention maps onto relevant constructs in this theory. For example, although some studies refer to the theory of planned behaviour (37), they appear to target only attitudes about the behaviour (pain management) and not other important determinants in this model such as subjective norms or perceived control. Although there is established evidence that parents may have misconceptions about pain and pain medications $(10,15)$, most interventions attempted to modify attitudes only via education. The limited efficacy of education is perhaps not surprising, given that this strategy is considered to be one of the weakest methods for attitude change (38). That said, as evidenced in the study by Chambers et al (24), even if attitude change is successful, it does not necessarily lead to behaviour change or improved pain management outcomes. Future studies may need to further examine determinants of pain management behaviour other than attitudes. Indeed, in this study, the most promising of the interventions appears to be behavioural, with scheduled dosing and reminders.

In addition to theory development, future intervention trials should consider other pragmatic issues in their intervention development and testing. For example, Internet-based resources have been used successfully in children with functional abdominal pain (39) and arthritis pain (40), and similar strategies could be used to prepare parents for managing their child's postoperative pain. An Internet-based resource has recently been launched to support the parents of children two to six years of age to manage their child's pain following day surgery (www.mychildisinpain. org.uk/). The impact of this website on parents' pain management practices has not yet been assessed, but it may provide an exemplar of how information can be provided to parents. Future studies should also consider the timing of interventions. In the majority of these studies, the timing of delivery of interventions was unclear, although it usually appeared to be just before surgery or just before discharge. Evidence suggests that the timing of preparation for procedures is important because information that is offered too close to the procedure may be distressing or not adequately recalled (41). Future studies should also include larger sample sizes (most groups in these studies included approximately 30 participants) and ensure the use of validated assessment tools $(42,43)$.

In terms of the current status on the management of postoperative pain at home, the present review demonstrates that children experience mild to moderate pain over the first three days after surgery. Given the modest findings in the trials in the present review, it is important to better understand the contributors to the treatment of children's pain at home and to design and evaluate interventions that are driven by both evidence and theory.

\section{Clinical and research recommendations}

- Clinicians should be aware that many children experience moderate pain at home following day surgery.

- Although providing education about pain and addressing misconceptions about analgesics may be important, clinicians should also provide explicit instructions on ATC dosing of analgesics and recommend the use of a timer to remind parents of scheduled doses.

- Future research should seek to better understand the barriers and facilitators to management of children's pain at home and this research should be informed by, and inform, theory.

- Future research should consider age, developmental factors and sex effects on children's postoperative pain and its management. Future research should also consider individualized pain treatment thresholds as an additional measure of outcome.

ACKNOWLEDGEMENTS: JMC is funded by a New Investigator Award from the Canadian Institutes of Health Research and holds operating funding from CIHR, the Nova Scotia Health Research Foundation, and the IWK Health Centre. The authors thank several of the authors of included manuscripts for their willingness to share their data for the purposes of this review.

\section{REFERENCES}

1. Finley GA, McGrath PJ, Forward PS, McNeill G, Fitzgerald P. Parents' management of children's pain following "minor" surgery. Pain 1996;64:83-87.

2. Fortier MA, MacLaren JE, Perrett-Karimi D, Kain ZN. Pediatric pain after ambulatory surgery: Where's the medication? Pediatrics 2009;134:e588-e595.

3. Shum S, Lim J, Page T, et al. An audit of pain management following pediatric day surgery at British Columbia Children's Hospital. Pain Res Manag 2012;17:328-34.

4. Joshi GP, Ogunnaike BO. Consequences of inadequate postoperative pain relief and chronic persistent postoperative pain. Anesthesiol Clin North America 2005;23:21-36.

5. Fortier MA, Chou J, Maurer EL, Kain ZN. Acute to chronic postoperative pain in children: Preliminary findings. J Pediatr Surg 2011;46:1700-5.

6. Pate JT, Blount RL, Cohen LL, Smith AJ. Childhood medical experience and temperament as predictors of adult functioning in medical situations. Child Health Care 1996;25:281-98.

7. Jonas DA. Parent's management of their child's pain in the home following surgery. J Child Health Care 2003;7:150-62. 
8. Huth MM, Broome ME. A snapshot of children's postoperative tonsillectomy outcomes at home. J Soc Pediatr Nurs 2007;12:186-95.

9. Paquette J, Le May S, Lachance Fiola J, Villeneuve E, Lapointe A, Bourgault P. A randomized controlled trial of nurse telephone follow-up on paediatric tonsillectomy pain management and complications. J Adv Nurs 2013;69:2054-65.

10. Zisk-Rony RY, Fortier MA, MacLaren-Chorney J, Perrett D, Zain ZN. Parental postoperative pain management: Attitudes, assessment and management. Pediatrics 2010;125:1372-8.

11. Kankkunen P, Vehvilainen-Julkunen K, Pietila A-M, Kokki H, Halonen P. Parents' perceptions and use of analgesics at home after children's day surgery. Paediatr Anaesthes 2003;13:132-40.

12. He H-G, Polkki T, Pietila A-M, Vehvilainen-Julkunen K. Chinese parent's use of nonpharmacological methods in children's postoperative pain relief. Scand J Caring Sci 2006;20:2-9.

13. Kankkunen P, Vehvilainen-Julkunen K, Pietila A-M, Halonen P. Parents' use of nonpharmacological methods to alleviate children's postoperative pain at home. J Adv Nurs 2003;41:367-75.

14. Forward PS, Brown TL, McGrath PJ. Mothers' attitudes and behavior toward medicating children's pain. Pain 1996;67:469-74.

15. Twycross A, Finley GA. Children's and parents' perceptions of postoperative pain management: A mixed methods study. J Clin Nurs 2013;22:3095-108.

16. Hamers JPH, Abu-Saad HH. Children's pain at home following (adeno)tonsillectomy. Eur J Pain 2002;6:213-9.

17. Kankkunen P, Vehvilainen-Julkunen K, Pietila A-M, Halonen P. Is the sufficiency of discharge instructions related to children's postoperative pain at home after surgery? Scand J Caring Sci 2003;17:365-72.

18. Gauthier JC, Finley GA, McGrath PJ. Children's self-report of postoperative pain intensity and treatment threshold: Determining the adequacy of medication. Clin J Pain 1998;14:116-20.

19. Voepel-Lewis T, Burke CN, Jeffreys N, Malviya S, Tait AR. Do 0-10 numeric rating scores translate into clinically meaningful pain measures for children? Anesthes Analges 2011;112:415-21.

20. Sutters KA, Savedra MC, Miaskowski C. The pediatric PROSELF pain control program: An effective educational program for parents caring for children at home following tonsillectomy. J Spec Pediatr Nurs 2011;16:280-94.

21. Cohen J. Statistical Power Analysis for the Behavioral Sciences, 2nd edn. Hillsdale: Lawrence Erlbaum Associates, 1988

22. Greenberg RS, Billett C, Zahurak M, Yaster M. Videotape increases parental knowledge about pediatric pain management. Pediatr Anesthes 1999;89:899-903.

23. Seid M, Varni JW. Pediatric day surgery outcomes management: The role of preoperative anxiety and a home pain management protocol. J Clin Outcomes Manag 1999;6:24-30.

24. Chambers CT, Reid GJ, McGrath PJ, Finley GA, Ellerton ML. A randomized trial of a pain education booklet: Effects on parents' attitudes and postoperative pain management. Children's Health Care 1997;26:1-13.

25. Franck LS, Allen A, Oulton K. Making pain assessment more accessible to children and parents: Can greater involvement improve the quality of care? Clin J Pain 2007;23:331-8.

26. Helgadottir HL. Education for parents to manage children's pain at home after tonsillectomy. University of Nebraska Medical Center, 2007
27. Kankkunen P, Vehvilainen-Julkunen K, Pietila A-M, et al. Promoting children's pharmacological post-operative pain alleviation at home. Pediatric Nursing 2009;35:298-303.

28. Sutters KA, Miaskowski C, Holdridge-Zeuner D, et al. A randomized clinical trial of the effectiveness of a scheduled oral analgesic dosing regimen for the management of postoperative pain in children following tonsillectomy. Pain 2004;110:49-55.

29. Sutters KA, Miaskowski C, Holdridge-Zeuner D, et al. A randomized clinical trial of the efficacy of scheduled dosing of acetaminophen and hydrocodone for the management of postoperative pain in children after tonsillectomy. Clin J Pain 2010;26:95-103.

30. Unsworth V, Franck LS, Choonara I. Parental assessment and management of children's postoperative pain: A randomised clinical trial. J Child Health Care 2007;11:184-94.

31. Vincent C, Chiappetta M, Beach A, et al. Parents' management of children's pain at home after surgery. J Spec Pediatr Nurs 2012;17:108-20.

32. Dworkin RH, Turk DC, Wyrwich KW, et al. Interpreting the clinical importance of treatment outcomes in chronic pain clinical trials: IMMPACT recommendations. J Pain Symptom Manage 2008;9:105-21.

33. Birnie KA, Chambers CT, McGrath PJ. When does pain matter? Acknowledging the subjectivity of clinical signficance. Pain 2012;153:2311-4.

34. Chambers CT, Giesbrecht K, Craig KD, Bennett S, Huntsman E. A comparision of faces scales for the measurement of pediatric pain: Children's and parents' ratings. Pain 1999;83:25-35.

35. Wilson DK, St. George SM, Zarrett N. Developmental influences in understanding child and adolescent health behaviors. In: Suls JM, Davidson KW, Kaplan RM, eds. Handbook of Health Psychology and Behavioral Medicine. New York: The Guilford Press, 2010:133-46.

36. Schmitz AK, Vierhaus M, Lohaus A. Pain tolerance in children and adolescents: Sex differences and psychosocial influences on pain threshold and endurance. Eur J Pain 2013;17:124-31.

37. Ajzen I. The theory of planned behavior. Organizational and Behavior and Human Decision Processes 1991;50:179-211.

38. Green LW. Should health education abandon attitude change strategies? Health Education Monographs 1970;30:25-48.

39. Sato A, Clifford L, Silverman A, Davies W. Cognitive-behavioral interventions via telehealth: Application to pediatric functional abdominal pain. Children's Health Care 2009;38:1-22

40. Stinson JN, McGrath PJ, Hodnett ED, et al. An internet based selfmanagement program with telephone support: A pilot randomized controlled trial. J Rheumatol 2010;37:1944-52.

41. Jaaniste T, Hayes B, von Baeyer CL. Providing children with information about forthcoming medical procedures: A review and synthesis. Clinical Psychology: Science and Practice 2007;14:124-43.

42. von Baeyer CL, Spagrud LJ. Systematic review of observational (behavioral) measures of pain for children and adolescents aged 3 to18 years. Pain 2007;127:140-50.

43. Stinson J, Yamada J, Kavanagh T, Gill N, Stevens B. Systematic review of the psychometric properties and feasibility of self-report pain measures for use in clinical trials in children and adolescents. Pain 2006;125:143-57. 


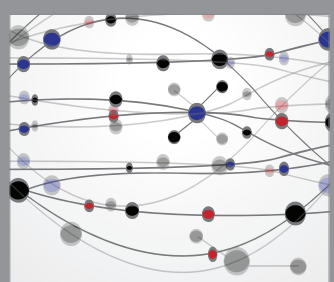

The Scientific World Journal
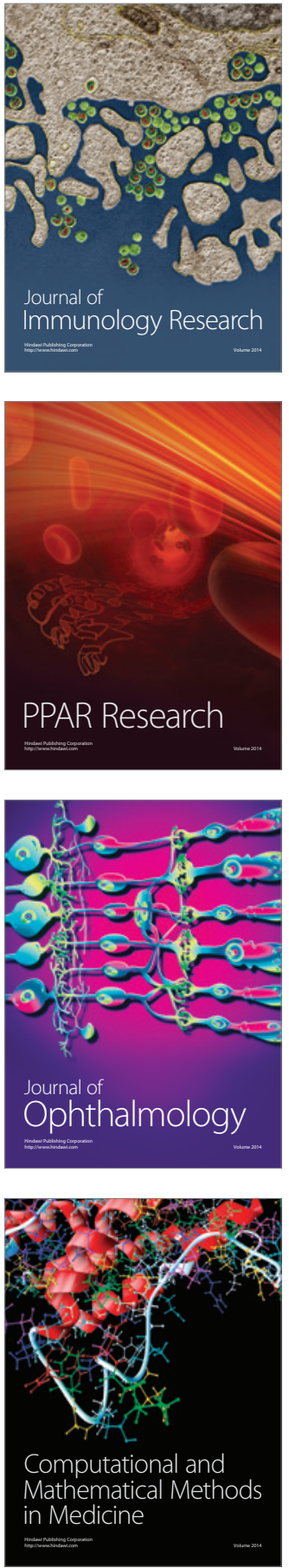

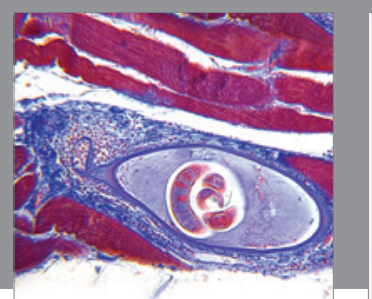

Gastroenterology Research and Practice

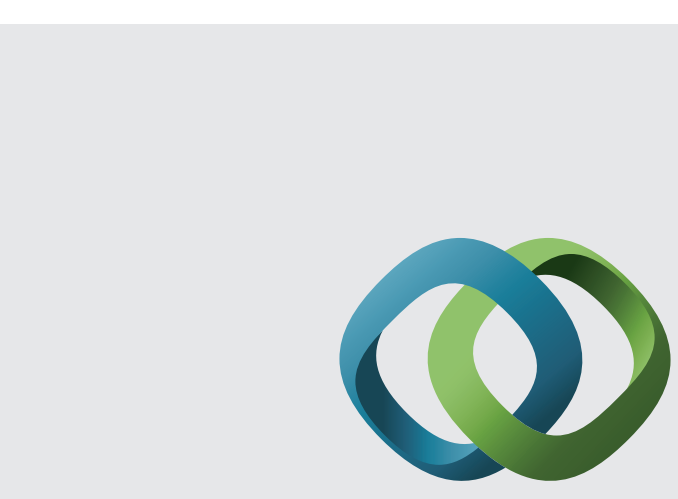

\section{Hindawi}

Submit your manuscripts at

http://www.hindawi.com
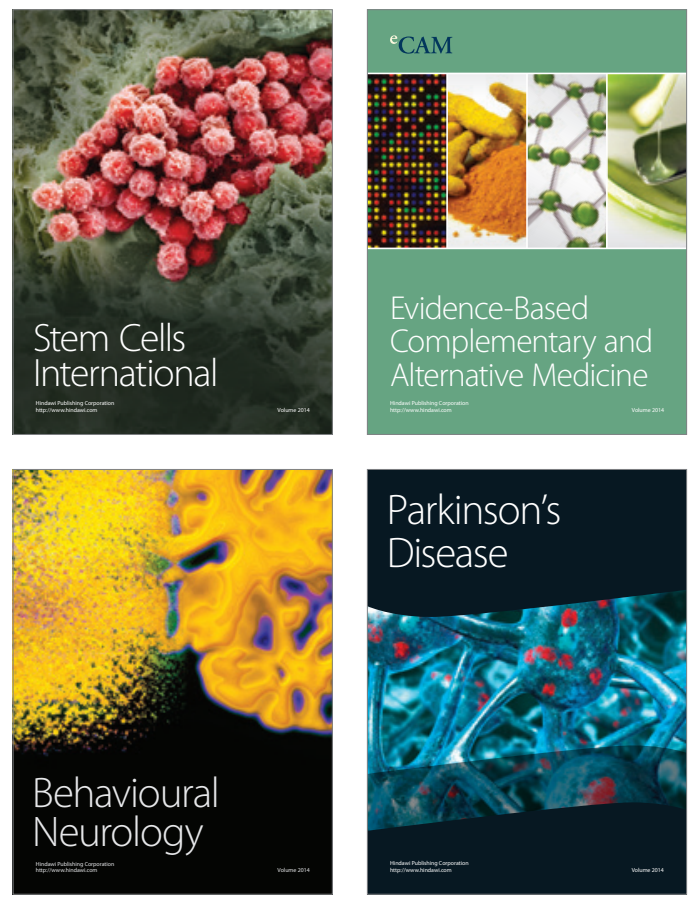
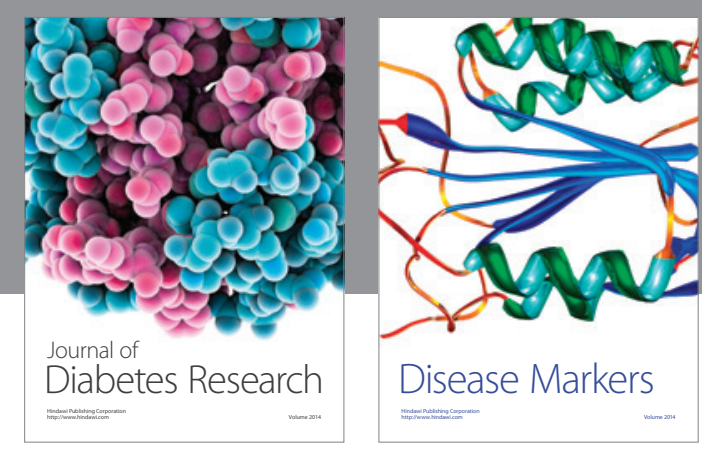

Disease Markers
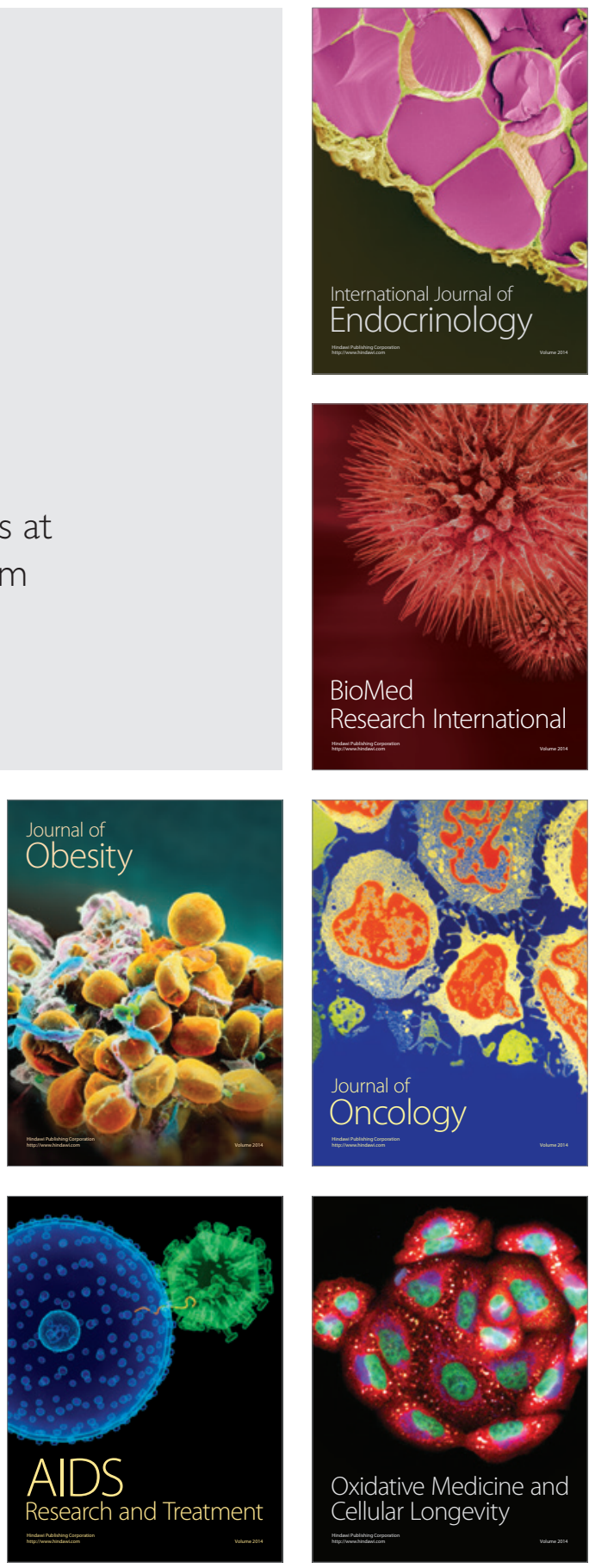